\title{
Trop-2 protein overexpression is an independent marker for predicting disease recurrence in endometrioid endometrial carcinoma
}

\author{
Eliana Bignotti ${ }^{1 *}$, Laura Zanotti ${ }^{1}$, Stefano Calza ${ }^{2,3}$, Marcella Falchetti ${ }^{4}$, Silvia Lonardi ${ }^{4}$, Antonella Ravaggi ${ }^{1}$, \\ Chiara Romani ${ }^{1}$, Paola Todeschini ${ }^{1}$, Elisabetta Bandiera ${ }^{1}$, Renata A Tassi ${ }^{1}$, Fabio Facchetti ${ }^{4}$, Enrico Sartori ${ }^{1}$, \\ Sergio Pecorelli ${ }^{1}$, Dana M Roque ${ }^{5}$ and Alessandro D Santin ${ }^{5}$
}

\begin{abstract}
Background: Endometrial cancer is the most common gynecologic malignancy in developed countries. Trop-2 is a glycoprotein involved in cellular signal transduction and is differentially overexpressed relative to normal tissue in a variety of human adenocarcinomas, including endometrioid endometrial carcinomas (EEC). Trop-2 overexpression has been proposed as a marker for biologically aggressive tumor phenotypes.

Methods: Trop-2 protein expression was quantified using tissue microarrays consisting of formalin-fixed paraffinembedded specimens from 118 patients who underwent surgical staging from 2001-9 by laparotomy for EEC. Clinicopathologic characteristics including age, stage, grade, lymphovascular space invasion, and medical comorbidities were correlated with immunostaining score. Univariate and multivariate analyses were performed for overall survival, disease-free survival, and progression-free survival in relation to clinical parameters and Trop-2 protein expression.
\end{abstract}

Results: Clinical outcome data were available for 103 patients. Strong Trop-2 immunostaining was significantly associated with higher tumor grade $(p=0.02)$ and cervical involvement $(p<0.01)$. Univariate analyses showed a significant association with reduced disease-free survival (DFS) $(p=0.01)$, and a trend towards significance for overall and progression-free survival ( $p=0.06$ and $p=0.05$, respectively). Multivariate analyses revealed Trop- 2 overexpression and advanced FIGO stage to be independent prognostic factors for poor DFS ( $p=0.04$ and $p<0.001$, respectively).

Conclusions: Trop-2 protein overexpression is significantly associated with higher tumor grade and serves as an independent prognostic factor for DFS in endometrioid endometrial cancer.

Keywords: Endometrioid endometrial cancer, Trop-2, TACSTD2, Tissue microarrays, Prognostic factor

\section{Background}

Endometrial cancer is the most common gynecologic malignancy in developed countries, with 47,130 new cases and 8,010 deaths projected for the United States alone in 2012 [1]. Endometrial carcinomas may be broadly dichotomized into two classes with distinct underlying molecular pathogenesis, clinical behavior, and histopathology [2]. Type I endometrial cancers comprise $80 \%$ of cases and are associated with a history of exposure to

\footnotetext{
* Correspondence: bignottieliana@yahoo.it

1"Angelo Nocivelli" Institute of Molecular Medicine, Division of Gynecologic Oncology, University of Brescia, Viale Europa 11, 25123 Brescia, Italy Full list of author information is available at the end of the article
}

unopposed estrogen, favorable prognosis, and endometrioid histology (grade 1 or 2) [3,4]; mutations in k-Ras, PTEN, or mismatch repair mechanisms predominate $[5,6]$. Type II endometrial cancers constitute the minority of cases, but are typified by an aggressive clinical course with a distinct pattern of metastasis, older age at presentation, the absence of antecedent history of unopposed estrogen, and serous, clear cell or grade 3 endometrioid histology [7,8]; aneuploidy, mutations in p53, and Her2/ Neu overexpression are common [9-12].

Trop-2 (also known as GA733-1, M1S1, EGP-1) is $35 \mathrm{kDa}$ transmembrane glycoprotein, encoded by the gene TACSTD2 of chromosome $1 \mathrm{p} 32$. Trop- 2 was originally

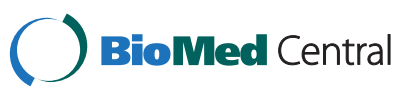


identified in human trophoblasts [13] and has been shown to be upregulated in a variety of human carcinomas [14-20]. Importantly, overexpression relative to normal tissue has been documented in ovarian, endometrial, and cervical cancers across a broad range of histologies including papillary serous [21-23] and endometrioid [24] adenocarcinomas, squamous cell carcinomas [25] and carcinosarcomas [26].

In the era of personalized molecular medicine, the role of intrinsic tumor biology is increasingly recognized as a major determinant in clinical course [27]. There is growing evidence that Trop- 2 overexpression portends adverse oncologic outcome [28-31]. This group has previously shown that strong expression as assessed by immunohistochemistry in epithelial ovarian cancers serves as an independent prognostic factor for decreased overall survival [32]. Recently, our group has also demonstrated that Trop-2 expression is significantly higher in endometrioid endometrial carcinomas (EEC) compared to normal tissues representing both proliferative and secretory phase endometrium, and that strength of immunohistochemistry staining correlates with increasing grade. Furthermore, compared to those that lack expression, EEC cell lines that overexpress Trop-2 are highly susceptible to antibody-dependent cellular cytotoxicity mediated by hRS7, a humanized monoclonal antibody against Trop-2 [24].

In this study, we perform secondary analyses of a subpopulation from our previous work. We describe for the first time the clinicopathologic significance of Trop-2 overexpression in EEC using a large number of specimens via tissue microarrays (TMAs). This investigation holds important implications for patient care, understanding the contribution of Trop- 2 to cancer pathogenesis, and further definition of the potential applications for therapy using hRS7 in the setting of treatmentrefractory disease.

\section{Methods}

\section{Endometrial carcinoma patients}

The tumor tissue samples included in this investigation were derived from 118 patients sequentially treated at the Division of Gynecologic Oncology, University of Brescia, Italy between 2001 and 2009. The study has been performed following the Declaration of Helsinki set of principles and it has been approved by the Research Review Board- the Ethic Committee- of the Spedali Civili, Brescia, Italy (study reference number: 527/B4/4).

The inclusion criteria for the patients were the following: i) diagnosis of endometrial adenocarcinoma, endometrioid in histology, ii) informed consent obtained from the patient and iii) sufficient amount of tumor tissue in the FFPE block to create the TMA. All pathology specimens were reviewed in our institution and histological classification was performed according to WHO criteria, while pathological stage was determined in accordance with guidelines of the International Federation of Gynecologists and Obstetricians (FIGO). Tumor tissues were obtained from women undergoing total abdominal hysterectomy, bilateral salpingo-oophorectomy and peritoneal washings. Lymph node sampling or dissection was predominantly performed in patients with tumors characterized by deep myometrial invasion and/or high grade or aggressive histology. Obesity and advanced age were relative contraindications to full surgical staging. None of the patients had received preoperative chemotherapy or radiation. Age, stage, grade, medical comorbidities (e.g., diabetes, obesity, hypertension) and treatment information were recorded in all cases. A total of 103 patients had sufficient follow-up for inclusion in survival analyses.

\section{Tissue microarrays and immunohistochemistry}

TMAs were created from 118 formalin-fixed, paraffinembedded EEC tissues collected from the Department of Surgical Pathology, University of Brescia, Italy. TMAs were built using an automated tissue microarrayer (TMA Master, 3DHistech, Budapest, Hungary). Representative areas were chosen for sampling from haematoxylin and eosin (H\&E) stained sections of selected normal endometrium (NE) and EEC cases. Four 0.6-mm cores were collected from different areas of each tumor block in order to overcome sample heterogeneity and the possible loss of tissue due to cutting. Separate TMAs were created for low and advanced tumor grade; normal tissue was included in all TMAs as an internal negative control. Four micron sections were cut from TMAs and H\&E staining was used for confirmation of tumor tissue. TMA sections were subjected to antigen retrieval $(40 \mathrm{~min}$ in water bath at $98^{\circ} \mathrm{C}$ in EDTA buffer $\mathrm{pH}$ 8.0) before application of the purified goat polyclonal antibody against the recombinant human Trop-2 extracellular domain (R\&D Systems, Inc., Minneapolis, MN) diluted 1:100. The antibody was revealed with a biotinylated rabbit anti-goat (Vector Labs, Burlingame, CA), diluted 1:250, followed by HRP-streptavidin (Dako, Glostrup, Denmark) and diaminobenzidine $(\mathrm{DAB})$ as chromogen; hematoxylin was used for counterstaining.

In the present investigation we used the immunohistochemical scoring method previously published by us in epithelial ovarian cancer [32]. Briefly, immunoreactivity was evaluated by three independent observers; membrane staining was graded for intensity (0-negative, 1-weak, 2 -moderate, and 3-strong) and the percentage of positive cells was scored as 0 (0\%), 1 (1-10\%), 2 (11-50\%), 3 (51-100\%). A single immunohistochemistry (IHC) scale 
with scores 0-9 was obtained by multiplying the intensity and the percentage staining score and a total score was calculated grouping score 0 in total score $0,1-3$ in total score 1,4 and 6 in total score 2 and 9 in total score 3. Digital images were resized by using Adobe Photoshop (Adobe Systems, Inc., San Jose, CA).

\section{Statistical analysis}

The association between Trop-2 immunohistochemical staining, coded as $0,1,2$ and 3 , and clinical covariates were evaluated by non-parametric one-way ANOVA and Wilcoxon-Mann-Whitney tests. For survival analysis, three endpoints (cancer relapse, cancer progression, and death due to cancer) were used to calculate disease-free survival (DFS), progression-free survival (PFS) and overall survival (OS), respectively. DFS was defined as the time interval between the date of surgery and the date of identification of disease recurrence, PFS was defined as the time interval between the date of surgery and the date of identification of progressive disease (disease not treatable with curative intent) and OS was defined as the time interval between the date of surgery and the date of death. For all three endpoints the last date of follow-up was used for censored subjects. Survival models were fitted using the Cox proportional hazard models, while survival curves were drawn based on the Kaplan-Meier methods. The association of Trop-2 immunostaining with prognosis was evaluated. In all analyses, a $\mathrm{p}$ value $<0.05$ was considered significant. All the analyses were performed using R (R Development Core Team, 2012) [33].

\section{Results}

Trop-2 immunostaining and clinicopathologic variables

The relationship between Trop-2 immunostaining and the clinical and pathologic features of the 118 endometrial carcinoma patients is shown in Table 1. Strong Trop-2 immunostaining was significantly associated with higher tumor grade $(\mathrm{p}=0.02)$, consistent with our previous results [24]. Moreover, Trop-2 protein overexpression was also significantly correlated with cervical involvement $(\mathrm{p}<0.01)$, and, marginally, with deeper myometrial invasion $(\mathrm{p}=0.08)$.

As previously reported by us, negative controls consisting in normal endometrial tissues demonstrated predominantly a weak immunoreactivity for Trop-2 (see Bignotti et al. 2011 [24] for figures representing Trop-2 immunostaining).

\section{Trop-2 immunostaining and patient survival}

The median follow-up interval was 48.7 months (range 6.1 - 124.9 months). At the time of the last follow up, 86 patients $(83.5 \%)$ were alive without evidence of disease, 1 patient (1\%) was alive with disease, and 16 patients (15.5\%) were dead of disease. The sites of recurrence were either local (pelvic lymph nodes, vaginal cupola), or distant (para-aortic lymph nodes, lung, brain, bone).

As expected, known EEC clinical prognostic factors, such as FIGO stage and lymph node involvement, showed a statistically significant association with OS, PFS and DFS in univariate analysis (all $\mathrm{p}<0.01$, Table 2). As displayed in Figure 1A and in Table 2, stronger Trop-2 immunostaining (IHC score 3 versus IHC score 0/1/2) showed a significant association with reduced DFS $(\mathrm{p}=0.01)$. Stronger Trop-2 immunostaining showed a trend towards significance for overall and progressionfree survival (Figure $1 \mathrm{~B}$ and $1 \mathrm{C}, \mathrm{p}=0.06$ and $\mathrm{p}=0.05$, respectively). Trop- 2 protein overexpression and advanced FIGO stage were identified as independent predictive factors for poor DFS $(\mathrm{p}=0.04$ and $\mathrm{p}<0.001$, respectively, Table 2) in multivariate analyses.

\section{Discussion}

In this study, we used tissue microarrays to demonstrate that Trop-2 protein overexpression is significantly associated with higher tumor grade as well as cervical involvement and serves as an independent prognostic factor for DFS in EEC. A trend towards significance between Trop-2 expression and OS and PFS was exhibited and would likely have been achieved for OS with larger sample size or longer median follow-up, as greater time is required to demonstrate differences in OS compared to other endpoints [34]. Nevertheless, DFS has been shown to be highly correlated with OS and is increasingly received as an acceptable endpoint [35]. These findings are consistent with previous reports that suggest that Trop- 2 overexpression identifies biologically aggressive phenotypes and poorly differentiated disease [24,28-31]. Though Trop-2 has been shown to be an excellent candidate antigen for targeted immunotherapy in multiple gynecologic malignancies including EEC [24], uterine papillary serous carcinomas [22], chemotherapy-resistant [23] and sensitive ovarian carcinomas [32], and cervical carcinomas [25], this is the first proof that Trop-2 overexpression can also prognosticate patient outcome in EEC.

The role of Trop-2 in cancer pathogenesis remains incompletely elucidated. In accordance with its original identification in trophoblasts, which possess the capacity to invade uterine decidua during the process of placental implantation, Trop- 2 may analogously confer to cancer cells the capacity for proliferation and invasion [36,37]. Wang et al. (2008) [38] demonstrated the role of Trop-2 in anchorage-independent growth and the oncogenic potential of Trop- 2 in colon cancer cells using both in vitro and in vivo models. Trop- 2 has been shown to directly mediate tumor-associated calcium-mediated signal cascades [39] and activation of ERK 1/2-MAPK pathways [36], both of which govern cell cycle progression $[40,41]$ and may protect cancer cells from apoptosis [42]. A 
Table 1 Clinical and pathologic characteristics of 118 endometrioid endometrial cancer patients and their association to Trop-2 protein expression

\begin{tabular}{|c|c|c|c|c|c|}
\hline \multicolumn{6}{|c|}{ Trop-2 protein expression } \\
\hline Variable & $\mathrm{n}$ & Score $\leq 1$ n (\%) & Score $=2$ n (\%) & Score $=3 n(\%)$ & p value* \\
\hline \multicolumn{6}{|l|}{ Age at diagnosis } \\
\hline \multirow[t]{2}{*}{$<65$} & 51 & $22(43.1)$ & $17(33.3)$ & $12(23.5)$ & \\
\hline & & & & & 0.89 \\
\hline$\geq 65$ & 67 & $28(41.8)$ & $26(38.8)$ & $13(19.4)$ & \\
\hline \multicolumn{6}{|l|}{ FIGO stage(2009 criteria) } \\
\hline \multirow[t]{2}{*}{$|-| \mid$} & 86 & $37(43)$ & $33(38.4)$ & $16(18.6)$ & \\
\hline & & & & & 0.56 \\
\hline III-IV & 22 & $8(36.4)$ & $6(27.3)$ & $8(36.4)$ & \\
\hline Unknown & 10 & $5(50)$ & $4(40)$ & $1(10)$ & \\
\hline \multicolumn{6}{|l|}{ WHO grading } \\
\hline \multirow[t]{2}{*}{ Grade 1} & 34 & $21(61.8)$ & $11(32.4)$ & $2(5.9)$ & \\
\hline & & & & & 0.024 \\
\hline Grade 2-3 & 84 & $29(34.5)$ & $32(38.1)$ & $23(27.4)$ & \\
\hline \multicolumn{6}{|l|}{ Myometrial invasion } \\
\hline \multirow[t]{2}{*}{$\mathrm{M} 0+\mathrm{M} 1$} & 55 & $26(47.3)$ & $22(40)$ & $7(12.7)$ & \\
\hline & & & & & 0.08 \\
\hline M2 & 63 & $24(38.1)$ & $21(33.3)$ & $18(28.6)$ & \\
\hline \multicolumn{6}{|l|}{ Lymph node status } \\
\hline \multirow[t]{2}{*}{ Negative } & 79 & $35(44.3)$ & $28(35.4)$ & $16(20.3)$ & \\
\hline & & & & & 0.69 \\
\hline Positive & 15 & $5(33.3)$ & $5(33.3)$ & $5(33.3)$ & \\
\hline Unknown & 24 & $10(41.7)$ & $10(41.7)$ & $4(16.7)$ & \\
\hline \multicolumn{6}{|l|}{ Cervical involvement } \\
\hline Absent & 83 & $37(44.6)$ & $33(39.8)$ & $13(15.7)$ & \\
\hline Glandular involvement & 16 & $10(62.5)$ & $4(25)$ & $2(12.5)$ & $<0.01^{\$}$ \\
\hline Stromal involvement & 18 & $3(16.7)$ & $6(33.3)$ & $9(50)$ & \\
\hline Unknown & 1 & $0(0)$ & $0(0)$ & $1(100)$ & \\
\hline \multicolumn{6}{|l|}{ Adnexal involvement } \\
\hline Negative & 108 & $45(41.7)$ & $42(38.9)$ & $21(19.4)$ & 0.97 \\
\hline Positive & 9 & $5(55.6)$ & $0(0)$ & $4(44.4)$ & \\
\hline Unknown & 1 & $0(0)$ & $1(100)$ & $0(0)$ & \\
\hline \multicolumn{6}{|l|}{ Peritoneal cytology } \\
\hline \multirow[t]{2}{*}{ Negative } & 100 & $40(40)$ & $37(37)$ & $23(23)$ & \\
\hline & & & & & 0.44 \\
\hline Positive & 8 & $4(50)$ & $2(25)$ & $2(25)$ & \\
\hline Unknown & 10 & $6(60)$ & $4(40)$ & $0(0)$ & \\
\hline \multicolumn{6}{|l|}{ Lymphovascular invasion } \\
\hline \multirow[t]{2}{*}{ Absent } & 48 & $22(45.8)$ & $20(41.7)$ & $6(12.5)$ & \\
\hline & & & & & 0.13 \\
\hline Present & 56 & $21(37.5)$ & $20(35.7)$ & $15(26.8)$ & \\
\hline Unknown & 14 & $7(50)$ & $3(21.4)$ & $4(28.6)$ & \\
\hline
\end{tabular}



to Trop-2 protein expression (Continued)

\begin{tabular}{|c|c|c|c|c|c|}
\hline \multicolumn{6}{|l|}{ Adjuvant Treatment } \\
\hline None & 57 & $31(54.4)$ & $20(35.1)$ & $6(10.5)$ & \\
\hline Radiotherapy & 36 & $12(33.3)$ & $13(36.1)$ & $11(30.6)$ & \\
\hline Chemotherapy & 8 & $3(37.5)$ & $1(12.5)$ & $4(50.0)$ & $0.094^{\$}$ \\
\hline Radiotherapy+Chemotherapy & 9 & $2(22.2)$ & $5(55.6)$ & $2(22.2)$ & \\
\hline Unknown & 8 & $5(62.5)$ & $2(25.0)$ & $1(12.5)$ & \\
\hline \multicolumn{6}{|l|}{ Parity } \\
\hline \multirow[t]{2}{*}{ Nulliparity } & 22 & $10(45.5)$ & $7(31.8)$ & $5(22.7)$ & \\
\hline & & & & & 0.72 \\
\hline Multiparity & 88 & $34(38.6)$ & $35(39.8)$ & 19 (21.6) & \\
\hline Unknown & 8 & $6(75)$ & $1(12.5)$ & $1(12.5)$ & \\
\hline \multicolumn{6}{|l|}{ Body Mass Index } \\
\hline \multirow[t]{2}{*}{$<25$} & 36 & $12(33.3)$ & $14(38.9)$ & $10(27.8)$ & \\
\hline & & & & & 0.58 \\
\hline$\geq 25$ & 64 & $27(42.2)$ & $24(37.5)$ & $13(20.3)$ & \\
\hline Unknown & 18 & $11(61.1)$ & $5(27.8)$ & $2(11.1)$ & \\
\hline \multicolumn{6}{|l|}{ Hypertension } \\
\hline \multirow[t]{2}{*}{ Negative } & 48 & $18(37.5)$ & $18(37.5)$ & $12(25)$ & \\
\hline & & & & & 0.26 \\
\hline Positive & 63 & $27(42.9)$ & $24(38.1)$ & $12(19)$ & \\
\hline Unknown & 7 & $5(71.4)$ & $1(14.3)$ & $1(14.3)$ & \\
\hline \multicolumn{6}{|l|}{ Diabetes } \\
\hline \multirow[t]{2}{*}{ Negative } & 96 & 38 (39.6) & $39(40.6)$ & 19 (19.8) & \\
\hline & & & & & 0.95 \\
\hline Positive & 15 & $8(53.3)$ & $2(13.3)$ & $5(33.3)$ & \\
\hline Unknown & 7 & $4(57.1)$ & $2(28.6)$ & $1(14.3)$ & \\
\hline \multicolumn{6}{|l|}{ Menopausal Status } \\
\hline \multirow[t]{2}{*}{ Premenopausal } & 18 & $7(38.9)$ & $5(27.8)$ & $6(33.3)$ & \\
\hline & & & & & 0.33 \\
\hline Postmenopausal & 94 & $39(41.5)$ & 37 (39.4) & $18(19.1)$ & \\
\hline Unknown & 6 & $4(66.7)$ & $1(16.7)$ & $1(16.7)$ & \\
\hline \multicolumn{6}{|l|}{ Smoking } \\
\hline \multirow[t]{2}{*}{ Negative } & 82 & $29(35.4)$ & $35(42.7)$ & $18(22)$ & \\
\hline & & & & & 0.91 \\
\hline Positive & 20 & $9(45)$ & $6(30)$ & $5(25)$ & \\
\hline Unknown & 16 & $12(75)$ & $2(12.5)$ & $2(12.5)$ & \\
\hline
\end{tabular}

* Exact Wilcoxon-Mann-Whitney test.

$\$$ Non-parametric ANOVA.

Unknown values were considered as missing and therefore excluded from the statistical analysis.

highly conserved phosphatidylinositol 4,5-bisphosphonate $\left(\mathrm{PIP}_{2}\right)$ binding sequence that overlaps with a protein kinase $\mathrm{C}$ phosphorylation sites within the cytoplasmic tail suggests a specific role in signal transduction $[43,44]$. Recently, Trerotola et al. [45] demonstrated that Trop-2 upregulation is necessary and sufficient to promote cell growth in different cancer cell types and that its somatic knockdown is able to extinguish tumor cell growth. The Trop-2 transcription control network, including factors activating Trop-2 expression or downstream growthstimulatory pathways has been recently reported [46]. Interestingly, Trop-2-cyclin D1 chimeric mRNAs have 
Table 2 Univariate and multivariate analyses of OS, DFS and PFS in relation to clinical parameters and Trop-2 protein expression

\begin{tabular}{|c|c|c|c|c|c|c|c|c|c|c|c|c|}
\hline \multirow[b]{2}{*}{ Variables } & \multicolumn{4}{|c|}{ OS } & \multicolumn{4}{|c|}{ DFS } & \multicolumn{4}{|c|}{ PFS } \\
\hline & $\mathrm{N}=97$ & HR & $95 \% \mathrm{Cl}$ & $\mathrm{p}$ & $\mathrm{N}=93$ & HR & $95 \% \mathrm{Cl}$ & $p$ & $\mathrm{~N}=97$ & HR & $95 \% \mathrm{Cl}$ & $\mathbf{p}$ \\
\hline \multicolumn{13}{|l|}{ Univariate analysis } \\
\hline \multicolumn{13}{|l|}{ Age } \\
\hline$<65$ vs $\geq 65$ & 103 & 1.23 & $0.46-3.28$ & 0.68 & 93 & 1.06 & $0.41-2.75$ & 0.90 & 102 & 1.37 & $0.49-3.79$ & 0.54 \\
\hline \multicolumn{13}{|l|}{ FIGO stage } \\
\hline |II-IV vs I-II & 97 & 17.05 & $5.47-53.17$ & $<0.01$ & 93 & 5.88 & $2.25-15.34$ & $<0.01$ & 96 & 16.73 & $5.28-53.03$ & $<0.01$ \\
\hline \multicolumn{13}{|l|}{ Tumor grade } \\
\hline G1 vs G2-G3 & 103 & 0.001 & $-*$ & 0.68 & 99 & 0.155 & $0.02-1.18$ & 0.07 & 102 & 0.001 & $-*$ & 0.69 \\
\hline \multicolumn{13}{|c|}{ Lymph node involvement } \\
\hline positive vs negative & 87 & 10.17 & $3.22-32.11$ & $<0.01$ & 85 & 6.05 & $2.09-17.51$ & $<0.01$ & 86 & 14.07 & $4.08-48.49$ & $<0.01$ \\
\hline \multicolumn{13}{|l|}{ Trop-2 IHC } \\
\hline score $=3$ vs score $0 / 1 / 2$ & 103 & 2.60 & 0.94-7.19 & 0.06 & 99 & 3.36 & $1.26-8.92$ & 0.01 & 102 & 2.80 & $0.99-7.87$ & 0.05 \\
\hline \multicolumn{13}{|l|}{ Multivariate analysis } \\
\hline Trop-2 IHC & 97 & & & & 93 & & & & 97 & & & \\
\hline score $=3$ vs score $0 / 1 / 2$ & & 1.83 & $0.65-5.18$ & 0.25 & & 2.82 & $1.05-7.58$ & 0.04 & & 1.76 & $0.63-4.88$ & 0.28 \\
\hline FIGO stage & 97 & & & & 93 & & & & 97 & & & \\
\hline |II-IV vs I-II & & 15.94 & $5.08-50.04$ & $<0.001$ & & 5.36 & $2.04-14.08$ & $<0.001$ & & 16.73 & $5.31-52.73$ & $<0.001$ \\
\hline
\end{tabular}

*Because of the small number of events (deaths and progressions) in the G1 EEC category, the confidence interval was not reliable.

also been identified in a variety of tumors and appear to lend enhanced stability to cyclin D1, resulting in cellular immortalization [47] and possibly prevention of anoikis [48]. Of note, Trop-2 expression appears to discriminate populations with stem-like activity [49], which may be important for initiation and perpetuation of cancers [50,51]. A different role of Trop-2 in cancer growth has been recently reported by Lin et al. [52] in lung carcinoma, where Trop- 2 is epigenetically downregulated and affected by $\mathrm{LOH}$, resulting in cancer progression via activation of IGF-1R signalling.

In this report, we provide immunostaining results indicative of protein expression. Immunohistochemistry is widely accepted as an adjunct technique to routine histologic analysis to offer additional diagnostic and prognostic information [53]. We did not evaluate Trop-2 at the mRNA level since transcript copy number and protein expression are poorly concordant for this antigen [32]. This phenomenon is not uncommon; genomic analyses at best are believed to capture only $40 \%$ of proteomic variations due to post-transcriptional regulatory mechanisms in mammalian cells [54].

Generally accepted prognostic factors for endometrial carcinoma are nodal involvement/stage, grade, and histologic subtype [55]. As anticipated, in this cohort Trop-2 overexpression correlated with grade and propensity for cervical involvement. Tumor location within the uterus has potential clinical relevance, since the lymphatic drainage of the cervix differs from that of the fundus in that it is much more rich and tends to involve the pelvic as opposed to the para-aortic nodes [56].

Many recent attempts to discover novel prognostic factors for endometrial cancer have been discouraging. Koyuncuoglu et al. (2012) [57] described the loss of e-cadherin expression in association with advanced stage and poor differentiation in both EEC and non-EEC, but failed to demonstrate statistical significance between ecadherin levels and survival using multivariate analyses. Similarly, while Mhawech-Fauceglia et al. (2012) [58] noted a high percentage of uterine papillary serous and EEC cases with expression of the tight junction protein claudin-7 and the cytoskeletal protein moesin, no association existed between these proteins and overall or disease-free survival.

\section{Conclusions}

In summary, we provide the first demonstration that Trop-2 overexpression prognosticates poor disease-free survival in EEC. This study corroborates previous reports on the importance of Trop-2 expression in human tumors to stratify biologically aggressive disease variants. Importantly, because Trop- 2 overexpression may represent an independent prognostic factor for earlier cancer recurrence, its determination in EEC tissue samples may be clinically useful in the attempt to identify patients at higher risk of relapse before surgery and, subsequently, 


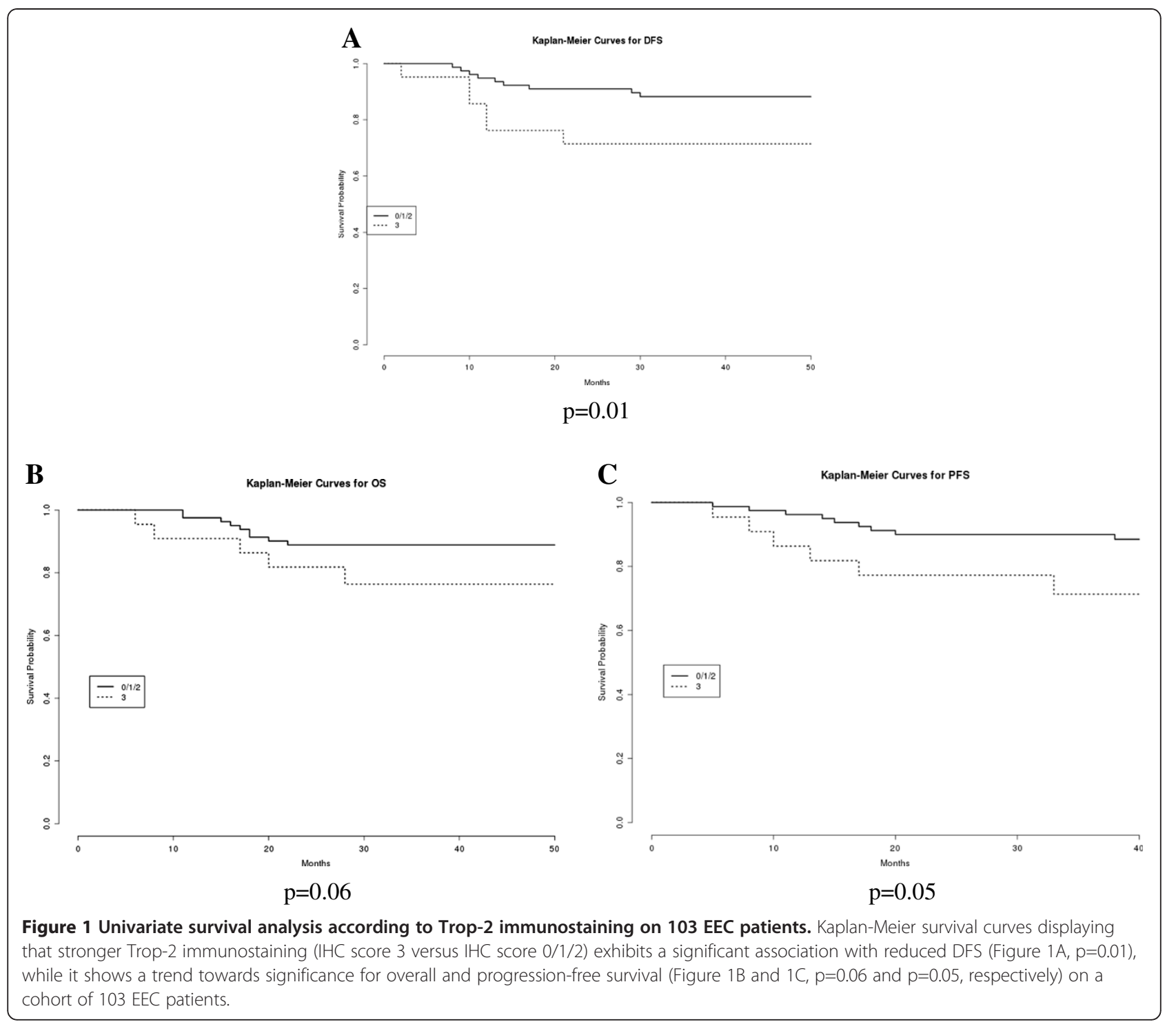

to optimize follow up and adjuvant treatments. These data, however, should be confirmed in additional studies on larger patient cohorts before routine Trop-2 IHC evaluation may be applied in the clinical setting.

\section{Competing interests}

The authors declare that they have no competing interests.

\section{Authors' contributions}

ADS conceived, coordinated, designed the study, interpreted the data and revised the manuscript. EB participated in the study design, created the patients'database, reviewed medical records, interpreted the data, drafted and wrote the report. LZ helped in reviewing the medical records and in drafting the manuscript. SC performed statistical analyses, created the tables, interpreted the data and helped to draft the manuscript. SL and MF performed pathological and immunohistochemical study. AR supervised the research group and critically reviewed the manuscript. EB and CR helped in collecting data from medical records and critically reviewed the manuscript. PT and RAT helped in collecting follow-up data and critically review the manuscript. FF coordinated the immunohistochemical study.
ES partecipated in the study design, interpreted the data and critically reviewed the manuscript. SP provided funds and participated in the design of the study. DR helped in drafting the manuscript discussion and critically review the paper. All of the authors read and approved the final manuscript.

\section{Acknowledgements}

We wish to thank Prof Piergiovanni Grigolato and Dr Carla Donzelli, for their excellent support to the project. We are also grateful to Dr Germana Tognon and Dr Franco E. Odicino for many helpful clinical discussions. Finally, we would like to thank all the nurses working in the $\mathrm{OR}$ and in the Division of Obstetrics and Gynecology, Spedali Civili di Brescia, Italy for the essential contribution in the collection of tissue samples.

This work was supported in part by grants from the Nocivelli Foundation Brescia, Italy and from the Istituto Superiore di Sanita' (Programma Italia-USA Oncoproteomica 527/B4/4), Rome, Italy to SP and by grants from NIH R01 CA122728-01A4 and R01 CA154460-01A1, the Honorable Tina Brozman Foundation, and Deborah Bunn Alley Ovarian Cancer Research Foundation to ADS. This investigation was also supported by NIH Research Grant CA16359 from the National Cancer Institute and by Fondazione Berlucchi, Brescia, Italy to FF. SL was supported by "Borsa di studio Prof Roberto Tosoni" (Garda Vita, BCC del Garda). 


\section{Author details}

1"Angelo Nocivelli" Institute of Molecular Medicine, Division of Gynecologic Oncology, University of Brescia, Viale Europa 11, 25123 Brescia, Italy. ${ }^{2}$ Department of Biomedical Sciences and Biotechnology, Section of Medical Statistics and Biometry, University of Brescia, Viale Europa 11, 25123 Brescia, Italy. ${ }^{3}$ Department of Medical Epidemiology and Biostatistics, Karolinska Institutet, SE-17177 Stockholm, Sweden. ${ }^{4}$ Department of Pathology, University of Brescia, Viale Europa 11, 25123 Brescia, Italy. ${ }^{5}$ Department of Obstetrics, Gynecology \& Reproductive Sciences, Yale University School of Medicine, 333 Cedar Street, PO Box 208063, New Haven CT 06520-8063, USA.

Received: 12 June 2012 Accepted: 7 November 2012

Published: 14 November 2012

\section{References}

1. Siegel R, Naishadham D, Jemal A: Cancer statistics-2012. CA Cancer J Clin 2012, 62:10-29.

2. Bohkman JV: Two pathogenetic types of endometrial carcinoma. Gynecol Oncol 1983, 15(1):10-17.

3. Amant F, Moerman P, Neven P, Timmerman D, Van Limbergen E, Vergote I: Endometrial cancer. Lancet 2005, 366:491-505.

4. Felix AS, Weissfeld JL, Stone RA, Bowser R, Chivukula M, Edwards RP, Linkov F: Factors associated with Type I and Type II endometrial cancer. Cancer Causes Control 2010, 21:1851-1856.

5. Sherman ME: Theories of endometrial carcinogenesis. Mod Pathol 2000, 13(3):295-298

6. Hecht JL, Mutter GL: Molecular and pathologic aspects of endometrial carcinogenesis. J Clin Oncol 2006, 24(29):4783-4791.

7. Goff BA, Kato D, Schmidt RA, Ek M, Ferry JA, Muntz HG, Cain JM, Tamimi HK, Figge DC, Greer BE: Uterine papillary serous carcinoma: pattern of metastatic spread. Gynecol Oncol 1994, 54:264-268.

8. Creasman W, Kohler M, Odicino, Maisonneuve P, Boyle P: Prognosis of papillary serous, clear cell, and grade 3 stage I carcinoma of the endometrium. Gynecol Oncol 2004, 95:593-596.

9. Lax SF, Kendall B, Tashiro H, Slebos RJ, Hedrick L: The frequency of p53, $\mathrm{K}$-Ras mutations, and microsatellite instability differs in uterine endometrioid and serous carcinoma-evidence of distinct molecular genetic pathways. Cancer 2000, 88:814-824.

10. Santin AD, Bellone S, Van Stedum S, Bushen W, De Las Casas LE, Korourian S, Tian E, Roman JJ, Burnett A, Pecorelli S: Determination of Her2/Neu status in uterine serous papillary carcinoma:comparative analysis of immunohistochemistry and fluorescence is situ hybridization. Gynecol Oncol 2005, 98:24-30.

11. Santin AD, Bellone S, Van Stedum S, Bushen W, Palmieri M, Siegel ER, De Las Casas LE, Roman JJ, Burnett A, Pecorelli S: Amplification of c-erbB2 oncogene: a major prognostic indicator in uterine serous papillary carcinoma. Cancer 2005, 104:1391-7.

12. Llauradó M, Ruiz A, Majem B, Ertekin T, Colás E, Pedrola N, Devis L, Rigau M, Sequeiros T, Montes M, Garcia M, Cabrera S, Gil-Moreno A, Xercavins J, Castellví J, Garcia A, Ramón Y, Cajal S, Moreno G, Alameda F, Vázquez-Levin M, Palacios J, Prat J, Doll A, Matías-Guiu X, Abal M, Reventós J: Molecular bases of endometrial cancer: new roles for new actors in the diagnosis and the therapy of the disease. Mol Cell Endocrinol 2011, doi:0.1016/j. mce.2011.10.003.

13. Lipinski M, Parks DR, Rouse RV, Herzenberg LA: Human trophoblast cellsurface antigens defined by monoclonal antibodies. Proc Natl Acad SCi 1981, 78:5147-5150.

14. Miotti S, Canevari S, Menard S, Mezzanzanica D, Porro G, Pupa SM, Regazzoni M, Tagliabue E, Colnaghi Ml: Characterization of human ovarian carcinoma-associated antigens defined by monoclonal antibodies with tumor-restricted specificity. Int J Cancer 1987, 39:297-303

15. Alberti S, Miotti S, Stella M, Klein CE, Fornaro M, Menard S, Colnaghi MI: Biochemical characterization of Trop-2, a cell surface molecule expressed by human carcinomas: formal proof that the monoclonal antibodies T16 and MOv-16 recognize Trop-2. Hybridoma 1992, 50:1330-1336.

16. Stein R, Basu A, Chen S, Shih LB, Goldenberg DM: Specificity and properties of MAb RS7-3G11 and the antigen defined by this pancarcinoma monoclonal antibody. Int J Cancer 1993, 55:938-496
17. Zhang I, Zhou W, Velculescu VE, Kern SE, Hruban RH, Hamilton SR, Vogelstein B, Kinzler KW: Gene expression profiles in normal and cancer cells. Science 1997, 276:1268-7122.

18. lacobuzio-Donahue CA, Maitra A, Shen-Ong GL, Shen-Ong GL, van Heek T, Ashfaq R, Meyer R, Walter K, Berg K, Hollingsworth MA, Cameron JL, Yeo CJ, Kern SE, Goggins M, Hruban RH: Discovery of novel tumor markers of pancreatic cancer using global gene expression technology. Am J Pathol 2002, 160:1239-1249.

19. Nakashima K, Shimada H, Ochai T, Kuboshima M, Kuroiwa N, Okazumi S, Matsubara H, Nomura F, Takiguchi M, Hiwasa T: Serological identification of Trop-2 by recombinant cDNA expression cloning using sera of patients with esophageal squamous cell carcinoma. Int J Cancer 2004, 112:1029-1035.

20. Birkenkamp-Demtroder K, Olesen SH, Sorensen FB, Laurberg S, Laiho P, Aaltonen LA, Orntoft TF: Differential gene expression in colon cancer of the caecum versus the sigmoid and rectosigmoid. Gut 2005, 54:374-384

21. Santin AD, Zhan F, Bellone S, Palmieri M, Cane S, Bignotti E, Anfossi S, Godken M, Dunn D, Roman JJ, O'Brien TJ, Tian E, Cannon MJ, Shaughnessy J $J r$, Pecorelli S: Gene expression profiles in primary ovarian serous papillary tumors and normal ovarian epithelium: identification of candidate molecular markers for ovarian cancer diagnosis and therapy. Int J Cancer 2004, 112(1):14-25.

22. Varughese J, Cocco E, Bellone S, de Leon M, Bellone M, Todeschini P, Schwartz PE, Rutherford TJ, Pecorelli S, Santin AD: Uterine serous papillary carcinomas overexpress human trophoblast cell surface marker (Trop-2) and are highly sensitive to immunotherapy with hRS7, a humanized anti-Trop-2 monoclonal antibody. Cancer 2011, 117:3163-3172.

23. Varughese J, Cocco E, Bellone S, Bellone M, Todeschini P, Carrara L, Schwartz PE, Rutherford TJ, Pecorelli S, Santin AD: High-grade, chemotherapy-resistant primary ovarian carcinoma cell lines overexpress human trophoblast cell-surface marker (Trop-2) and are highly sensitive to immunotherapy with hRS7, a humanized monoclonal anti-Trop-2 antibody. Gynecol Oncol 2011, 122:171-177.

24. Bignotti E, Ravaggi A, Romani C, Falchetti M, Lonardi S, Facchetti F, Pecorelli S, Varughese J, Cocco E, Bellone S, Schwartz PE, Rutherford TJ, Santin AD: Trop-2 overexpression in poorly differentiated endometrial endometrioid carcinoma: implications for therapy with hRS7, a humanized anti-Trop2monoclonal antibody. Int J Gynecol Cancer 2011, 21:1613-1621.

25. Varughese J, Cocco E, Bellone S, Ratner E, Silasi DA, Azodi M, Schwartz PE, Rutherford TJ, Buza N, Pecorelli S, Santin AD: Cervical carcinomas overexpress human trophoblast cell-surface marker (Trop-2) and are highly sensitive to immunotherapy with hRS7, a humanized monoclonal anti-Trop-2 antibody. Am J Obstet Gynecol 2011, 205:567.e1-567.e7.

26. Raji R, Guzzo F, Carrara L, Varughese J, Cocco E, Bellone S, Betti M, Todeschini P, Gasparrini S, Ratner E, Silasi DA, Azodi M, Schwartz P, Rutherford TJ, Buza N, Pecorelli S, Santin AD: Uterine and ovarian carcinosarcomas overexpressing Trop-2 are sensitive to hRS7, a humanized anti-rop-2 antibody. J Exp Clin Cancer Res 2011, 30:106-112.

27. Esselen KM, Boruta DM, del Carmen M, Schorge JO, Goodman A, Growdon WB: Defining prognostic variables in recurrent endometrioid endometrial cancer: a 15-year single-institution review. Int J Gynecol Cancer 2011, 21:1078-1083.

28. Ohmachi T, Tanaka F, Mimori K, Inoue H, Yanaga K, Mori M: Clinical significance of Trop-2 expression in colorectal cancer. Clin Cancer Res 2006, 12:3057-3063.

29. Fong D, Moser P, Krammel C, Gostner JM, Margreiter R, Mitterer M, Gastl G, Spizzo G: High expression of Trop-2 correlates with poor prognosis in pancreatic cancer. Br J Cancer 2008, 99(8):1290-1295.

30. Fong D, Spizzo G, Gostner JM, Gostner JM, Margreiter R, Mitterer M, Gastl G, Spizzo G: Trop-2, a novel prognostic marker in squamous cell carcinoma of the oral cavity. Mol Pathol 2008, 21:186-191.

31. Muhlmann G, Spizzo G, Gostner J, Zitt M, Maier H, Moser P, Gastl G, Zitt M, Müller HM, Margreiter R, Ofner D, Fong D: Trop-2 expression as prognostic marker for gastric carcinoma. J Clin Pathol 2009, 62:152-158.

32. Bignotti E, Todeschini P, Calza S, Falchetti M, Ravanini M, Tassi RA, Ravaggi A, Bandiera E, Romani C, Zanotti L, Tognon G, Odicino FE, Facchetti F, Pecorelli S, Santin AD: Trop-2 overexpression as an independent marker for poor overall survival in ovarian carcinoma patients. Eur J Cancer 2010, 46:944-953.

33. R Development Core Team (2012): R-A language and environment for statistical computing. http://www.R-project.org. 
34. Punt $C$, Buyse $M$, Köhne $C$, Hohenberger $P$, Labianca $R$, Schmoll HJ, Påhlman $L$, Sobrero A, Douillard J: Endpoints in adjuvant treatment trials: a systematic review of the literature in colon cancer and proposed definitions for future trials. J Natl Cancer Inst 2007, 99:998-1003.

35. Sargent D, Wieand HS, Haller DG, Gray R, Benedetti JK, Buyse M, Labianca R, Seitz JF, O'Callaghan CJ, Francini G, Grothey A, O'Connell M, Catalano PJ, Blanke CD, Kerr D, Green E, Wolmark N, Andre T, Goldberg RM, De Gramont $A$ : Disease-free survival versus overall survival as a primary endpoints for adjuvant colon cancer studies: individual data from 20898 patients on 18 randomized trials. J Clin Oncol 2005, 23:8864-8670.

36. Cubas R, Zhang S, Li M, Chen C, Yao Q: Trop-2 expression contributes to tumor pathogenesis by activating the ERK MAPK pathway. Molec Cancer 2010, 9:253-265.

37. Cubas R, Li M, Chen C, Yao Q: Trop2-A possible therapeutic target for late stage epithelial carcinomas. Biochim Biophys Acta 2009, 1796:309-314.

38. Wang J, Day R, Dong Y, Weintraub SJ, Michel L: Identification of Trop-2 as an oncogene and an attractive therapeutic target in colon cancers. $\mathrm{Mol}$ Cancer Ther 2008, 7:280-285.

39. Ripani E, Sacchetti A, Corda D, Alberti S: Human Trop-2 is a tumorassociated calcium signal transducer. Int J Cancer 1998, 76(5):671-6.

40. Whitaker M: Larman: Calcium and mitosis. Semin Cell Devel Biol 2001, 12:53-58.

41. Meloche S, Pouyssegur J: The ERK $1 / 2$ mitogen-activated protein kinase pathway as a master regulator of the G1-to-S-phase transition. Oncogene 2007, 26:3227-3239.

42. Boucher M, Morisset J, Vachon PH, Reed JC, Lainé J, Rivard N: MEK/ERK signaling pathway regulates the expression of $\mathrm{BCl}-2, \mathrm{BCl}-\mathrm{Xl}$, and $\mathrm{Mcl}-1$ and promotes survival of human pancreatic cancer cells. J Cell Biochem 2000, 79:355-639.

43. El Sewedy T, Fornaro M, Alberti S: Cloning of the murine Trop2 geneconservation of a PIP2-binding sequence in the cytoplasmic domain of Trop2. Int J Cancer 2008, 75:324-30.

44. Basu A, Goldenberg DM, Stein R: The epithelial/carcinoma antigen EGP-1, recognized b monoclonal antibody RS7-3G11, is phosphorylated on serine 303. Int J Cancer 1995, 62:472-479.

45. Trerotola M, Cantanelli P, Guerra E, Tripaldi R, Aloisi AL, Bonasera V, Lattanzio R, Lange RD, Weidle UH, Piantelli M, Alberti S: Upregulation of Trop-2 quantitatively stimulates human cancer growth. Oncogene 2012, doi:10.1038/onc.2012.36.

46. Guerra E, Trerotola M, Aloisi AL, Tripaldi R, Vacca G, La Sorda R, Lattanzio R, Piantelli M, Alberti S: The Trop-2 signalling network in cancer growth. Oncogene 2012, doi:10.1038/onc.2012.151.

47. Guerra E, Trerotola M, Dell' Arciprete R, Bonasera V, Palombo B, El-Sewedy T, Ciccimarra T, Crescenzi C, Lorenzini F, Rossi C, Vacca G, Lattanzio R, Piantelli M, Alberti S: A bicistronic CYCLIN D1-TROP2 mRNA chimera demonstrates a novel oncogenic mechanism in human cancer. Cancer Res 2008, 68:8113-8121.

48. Gan L, Liu P, Lu H: Cyclin D1 promotes anchorage-independent cell survival by inhibiting FOXO-mediated anoikis. Cell Death Differ 2009, 16:1408-1417.

49. Goldstein AS, Lawson DA, Cheng D, Sun W, Garraway IP, Witte ON: Trop-2 identifies a subpopulation of murine and human prostate basal cells with stem cell characteristics. Proc Natl Acad Sci 2008, 105:20882-20887.

50. Ginestier C, Hur MH, Charafe-Jauffret E, Monville F, Dutcher J, Brown M, Jacquemier J, Viens P, Kleer CG, Liu S, Schott A, Hayes D, Birnbaum D, Wicha MS, Dontu G: ALDH1 is a marker of normal and malignant human mammary stem cells and a predictor of poor clinical outcome. Cell Stem Cell 2007, 1:555-567

51. Malanchi I, Peinado H, Kassen D, Hussenet T, Metzger D, Chambon P, Huber M, Hohl D, Cano A, Birchmeier W, Huelsken J, et al: Cutaneous cancer stem cell maintenance is dependent on beta-catenin signalling. Nature 2008, 3:650-633.

52. Lin JC, Wu YY, Wu JY, Lin TC, Wu CT, Chang YL, Jou YS, Hong TM, Yang PC: TROP2 is epigenetically inactivated and modulates IGF-1R signalling in lung adenocarcinoma. EMBO Mol Med 2012, 4(6):472-85. doi:10.1002/ emmm.201200222.

53. Chieng DC, Rodriguez-Buford C, Grizzle WA: Role of immunohistochemical expression of Lewis $Y$ antigen in ovarian carcinoma. In Immunohistochemistry and In Situ Hybridization of Human Carcinomas, Vol 4. Edited by Hayat MA. Burlington, MA: Elsevier Academic Press; 2006:465-471.
54. Tian Q, Stepaniants SB, Mao M, Weng L, Feetham MC, Doyle MJ, Yi EC, Dai H, Thorsson V, Eng J, Goodlett D, Berger JP, Gunter B, Linseley PS, Stoughton RB, Aebersold R, Collins SJ, Hanlon WA, Hood LE: Integrated genomic and proteomic analyses of gene expression in mammalian cells. Mol Cell Proteomics 2004, 3:960-969.

55. Brown AK, Madom L, Moore R, Granai CO, DiSilvestro P: The prognostic significance of lower uterine segment involvement in surgically staged endometrial cancer patients with negative nodes. Gynecol Oncol 2007, 105:55-58.

56. Levenback CF: Status of sentinel lymph node biopsy in gynecological cancers. Ann Surg Oncol 2008, 15:18-20.

57. Koyuncuoglu M, Okyay E, Saatli B, Olgan S, Akin M, Saygili U: Tumor budding and e-cadherin expression in endometrial carcinoma: are they prognostic factors in endometrial cancer? Gynecol Oncol 2012, 125:208-213.

58. Mhawech-Fauceglia P, Wang D, Lele S, Frederick PJ, Pejovic T, Liu S: Claudin-7 and moesin in endometrial adenocarcinoma-aretrospective study of 265 patients. BMC Research Notes 2012, 5:65-71.

doi:10.1186/1472-6890-12-22

Cite this article as: Bignotti et al:: Trop-2 protein overexpression is an independent marker for predicting disease recurrence in endometrioid endometrial carcinoma. BMC Clinical Pathology 2012 12:22.

\section{Submit your next manuscript to BioMed Central and take full advantage of:}

- Convenient online submission

- Thorough peer review

- No space constraints or color figure charges

- Immediate publication on acceptance

- Inclusion in PubMed, CAS, Scopus and Google Scholar

- Research which is freely available for redistribution 